\title{
PENGARUH SERTIFIKAT BANK INDONESIA SYARIAH (SBIS), JAKARTA ISLAMIC INDEX (JII), TINGKAT INFLASI, DAN INDEX HARGA SAHAM GABUNGAN (IHSG) TERHADAP NILAI TUKAR : PENDEKATAN AUTOREGRESSIVE DISTRIBUTED LAG (ARDL) ${ }^{1]}$
}

\author{
Nur Fadhilah \\ Mahasiswa Program Studi S1 Ekonomi Islam- Fakultas Ekonomi dan Bisnis-Universitas Airlangga \\ Email: nur.fadhiah-13@feb.unair.ac.id \\ Raditya Sukmana \\ Departemen Ekonomi Syariah- Fakultas Ekonomi dan Bisnis-Universitas Airlangga \\ Email: raditya-s@feb.unair.ac.id
}

\begin{abstract}
:
This study aims to review the effect of macro economic factors such as Bank Indonesia Sharia Certificates (BISC), Jakarta Islamic Index (JII), Inflation, and Indonesia Composit Index (ICI) Against Exchange Rate of Rupiah Period 2013-2016 both long term and short term. This quantitative research used Autoregressive Distributed (ARDL) method. The data used is secondary data by collecting data from official website of Bank Indonesia, Yahoo Finance and PT. IDX) period 2013 to 2016. ARDL results show that In the short term variable $\mathrm{JII}, \mathrm{ICl}$, and BISC have a significant negative effect which means increaseing the variable will cause the Rupiah appreciate against the US Dollar. While variable Inflation has a positive value which means rising inflation will lead the Rupiah depreciate. In the Long run $\mathrm{BISC}$ and $\mathrm{JII}$ variable is negative and significant, while $\mathrm{ICl}$ is positive and inflation is negative not-significant.
\end{abstract}

Keywords: ARDL, Exchange Rate, Stock Price, Islamic Macro Economic

\section{Pendahuluan}

Pada 26 Oktober 1946, pemerintah Indonesia dengan tegas dan berani mengeluarkan mata uang sendiri dan melarang penggunaan mata vang asing jenis manapun. Sejak saat itu, Indonesia resmi mempunyai mata uang sendiri yang digunakan sebagai alat pembayaran yang sah, yaitu Rupiah. Uang merupakan instrument yang sangat penting dalam transaksi komersil baik dalam negeri maupun luar negeri. Setiap negara memiliki mata vang sendiri yang nilainya tentu berbeda antara satu negara dengan negara lain. Agar tercipta kesepakatan antar negara, maka muncul adanya kurs tukar atau nilai tukar yang disepakati antar dua negara. Mengingat pentingnya fungsi vang dalam perekonomian, pemerintah senantiasa berusaha agar nilai tukar rupiah selalu stabil dan terkendali (bi.go.id).

Menurut data BPS (2016), Pertumbuhan ekonomi kuartal ke-l pada tahun 2015 menjadi yang terendah dalam 10 tahun terakhir, yakni hanya di kisaran $4,7 \%$. Selanjutnya pada kuartal ke-III nilai tukar Rupiah terhadap Dolar Amerika juga sempat mencapai angka terendah yaitu IDR 14.802/USD. Pilkada serentak yang diselenggarakan pada tahun ini juga mempengaruhi dunia politik dan perekonomian Indonesia. Untuk itu pemerintah melalui Bank Indonesia sebagai Bank Sentral Republik Indonesia mempunyai tugas yang cukup berat yaitu 
Fadhilah, et al/Jurnal Ekonomi Syariah Teori dan Terapan Vol. 4 No. 10 Oktober 2017: 833-846; PENGARUH SERTIFIKAT BANK INDONESIA SYARIAH (SBIS), JAKARTA ISLAMIC INDEX (JII), TINGKAT INFLASI, DAN INDEX HARGA SAHAM GABUNGAN (IHSG) TERHADAP NILAI TUKAR : PENDEKATAN AUTOREGRESSIVE DISTRIBUTED LAG (ARDL)

melaksanakan kewajiban mengatur stabilitas nilai tukar Rupiah agar perekonomian tetap aman dan terkendali.

Perubahan nilai tukar mata vang antara satu negara dengan negara lain disebabkan oleh adanya permintaan dan penawaran. Selain itu ada juga adanya teori yang mengungkapkan bahwa harga barang komoditas antara satu negara dengan negara lainnya akan cenderung sama, yang kita kenal dengan Purchasing Power Parity (PPP) atau teori satu harga. Hal ini disebabkan apabila harga suatu komoditas berbeda dimana negara yang satu lebih murah dari negara lainnya, maka masyarakat akan memilih yang lebih murah. Namun pada kenyataannya, nilai tukar tidak hanya dipengaruhi oleh barang komoditas, namun juga dipengaruhi oleh faktor-faktor makro ekonomi lain Ramasamy (2015). Adapun yang akan dibahas pada jurnal ini adalah faktor makro ekonomi seperti Index Harga Saham Gabungan (IHSG), Tingkat Inflasi, Jakarta Islamic Index, dan Sertifikat Bank Indonesia Syariah.

\section{Studi Literatur}

Ada banyak studi penelitian tentang faktor-faktor yang mempengaruhi nilai tukar mata uang domestik terhadap mata uang asing. Salah satu penelitian diakukan oleh Katarzyna (2014) tentang pengaruh pertumbuhan ekonomi yang dilihat dari GDP, inflasi, suku bunga, neraca pembayaran, anggaran defisit pemerintah, dan pasar valas terhadap nilai tukar mata vang Polandia. Penelitian ini dilakukan dengan menggunakan metode analisis regresi linier berganda dan studi literatur. Hasil peneitian ini menyatakan bahwa ada pengaruh signifikan antara variable dependen terhadap variable independen.

Pada studi lainnya, Mohsen Bahmani (2010) meneliti pengaruh harga saham terhadap nilai tukar di 9 negara berbeda termasuk Indonesia dengan menggunakan metode Autoregressive Distribution Lag. Hasil penelitian ini menyatakan bahwa pengaruh antara variable baik jangka pendek maupun jangka panjang berbeda beda antara satu negara dengan negara lainnya. Hal ini disebabkan karena adanya faktor lain diluar variable yang diteliti. Hasil dari penelitian ini lebih lanjut akan dibahas pada bab II bersamaan dengan penelitian lainnya.

Ravindran dan Soroush (2015) juga melakukan penelitian serupa, yaitu meneliti tentang 10 faktor makroekonomi yang dianggap mempengaruhi nilai tukar mata vang Ringgit Malaysia, dengan menggunakan metode analisis regresi. Namun Mayoritas variable menunjukan hasil yang berbeda dari yang diharapkan, terutama variable suku bunga, BOP, dan inflasi. Hal ini menegaskan bahwa ada kemungkinan bahwa variable-variabel yang dianggap mempengaruhi nilai tukar bisa saja nilainya berbeda dari yang diharapkan. 
Fadhilah, et al/Jurnal Ekonomi Syariah Teori dan Terapan Vol. 4 No. 10 Oktober 2017: 833-846; PENGARUH SERTIFIKAT BANK INDONESIA SYARIAH (SBIS), JAKARTA ISLAMIC INDEX (JII), TINGKAT INFLASI, DAN INDEX HARGA SAHAM GABUNGAN (IHSG) TERHADAP NILAI TUKAR : PENDEKATAN AUTOREGRESSIVE DISTRIBUTED LAG (ARDL)

Menurut studi jurnal yang dilakukan oleh Richard \& John (2009) di Australia, Harga saham merupakan salah satu faktor yang cukup signifikan mempengaruhi Nilai Tukar. Mereka menganalisis adanya apresiasi nilai tukar sebesar satu per tiga poin ketika index saham meningkat dua per tiga poin. Nilai indeks saham dalam suatu pasar saham sangat mempengaruhi spekulasi investor. Pada umumnya, meningkatnya nilai saham suatu indeks menandakan bahwa perusahaan yang terlibat dalam indeks trsebut sedang mengalami peningkatan. Hal ini akan mendorong investor untuk menanamkan modalnya dan berinvestasi disana, sehingga nilai tukar Rupiah akan mengalami apresiasi akibat meningkatnya jumlah permintaan Rupiah. Namun ketika investor asing menjual sahamnya dan kelvar dari pasar saham Indonesia, hasil penjualan tersebut akan ditukarkan kedalam Dollar AS sehingga permintaan Dollar AS meningkat.

\section{Metodologi}

Menurut pedoman pengguan Eviews 9 (2016), ARDL adalah metode regresi yang memasukkan lag dari kedua variable dependen dan independen secara bersamaan. Dengan menggunakan model ini, kita bisa menganalisis hubungan jangka panjang ketika variabel variabel penjelasnya campuran antara yang bersifat I(1) dan 1(0). Estimator ARDL akan meghasilkan koefisien jangka panjang yang konsisten. Salah satu keunggulan dari pendekatan
ARDL ini adalah menghasilkan estimasi yang konsisten dengan koefisien jangka panjang yang bagus tanpa peduli apakah variabel-variabel penjelasnya atau regresornya I(0) ataupun I(1). Dalam kasus adanya hubungan jangka panjang yang bersifat trend stationarity, dengan ARDL dapat dilakukan detrending terhadap series dan memodelkan detrended series tersebut sebagai distributed lag yang stasioner. (Falianty, 2003).

Bila variable-variabel yang diamati membentuk suatu himpunan variable yang saling berkointegrasi, maka model dinamis yang cocok untuk mencari keseimbangan jangka pendek adalah model koreksi kesalahan (Error Correction Model/ECM). Selanjutnya, model koreksi kesalahan akan menjadi model yang valid bilamana variable-variabel yang berkointegrasi tersebut didukung oleh Error Correction Term (ECT) yang signifikan negative secara statistik (Salomo, 2007)

Estimasi jangka pendek pada model dilakukan dengan menggunakan metode general to specific yang diawali dengan lag maksimum lalu dengan prosedur tes standar untuk mengeliminasi variable-variabel yang secara statistik tidak signifikan. Lag maksimum yang digunakan berdasarkan Akaike Criterion (AIC) pada VAR Lag Order selection criteria. Langkah selanjutnya adalah melakukan reduksi dari lag maksimum tersebut mulai dari lag terpanjang dengan mengaplikasikan metode general 
Fadhilah, et al/Jurnal Ekonomi Syariah Teori dan Terapan Vol. 4 No. 10 Oktober 2017: 833-846; PENGARUH SERTIFIKAT BANK INDONESIA SYARIAH (SBIS), JAKARTA ISLAMIC INDEX (JII), TINGKAT INFLASI, DAN INDEX HARGA SAHAM GABUNGAN (IHSG) TERHADAP NILAI TUKAR : PENDEKATAN AUTOREGRESSIVE DISTRIBUTED LAG (ARDL)

to specific pada model. Reduksi dilakukan terhadap parameter parameter yang tidak signifikan sehingga didapatkan estimasi yang paling sederhana (parsimonious regression). Namun karena pada penelitian ini peneliti menggunakan Eviews 9 yang sudah dilengkapi opsi ARDL, langkah ini sudah otomatis diporses oleh Eviews 9 sehingga tidak perlu dilakukan secara manual (Falianty, 2003).

Sekumpulan variabel yang termasuk dalam model ARDL dapat diikuti dengan sejumlah regresor deterministik, seperti intersep, tren waktu, dan regresor dengan fixed lag. Dalam spesifikasi ARDL harus ditentukan maximum lag order-nya. Menurut Professor Dave Giles (2013), secara umum model regresi ARDL adalah sebagi berikut:

$$
\begin{aligned}
& y t=\beta 0+\beta 1 y t-1+\ldots \ldots+\beta k y t-p+a 0 x t+ \\
& a l x t-1+a 2 x t-2+\ldots \ldots \ldots+a q x t-q+\varepsilon t
\end{aligned}
$$

dimana:

¿† $\quad$ : random disturbance term

Model ARDL juga bisa terdiri dari regresor deterministik lainnya dengan fixed lag distributions. Pilihan model ARDL ini menawarkan prosedur alternatif (seperti kriteria AIC dan SBC) untuk memilih model mana yang optimal. Makin kecil nilai AIC akan semakin baik, sehingga penentuan spesifikiasi ordo lag dengan kriteria ini adalah dengan memilih lag dengan nilai AIC terendah. Pada dasarnya SBC (Schwarz Bayesian Criterion) memiliki fungsi yang sama dengan AIC, hanya saja
SBC memberikan penalti yang lebih besar untuk tambahan koefisien (Falianty, 2003).

Secara garis besar, langkah-langkah yang akan dilakukan untuk analisis ekonometri dengan menggunakan metode ini adalah sebagai berikut :

1) Menguji stasioneritas data variabelvariabel dalam model penelitian, baik pada tingkat level maupun tingkat first difference.

2) Menguji adanya kointegrasi pada Model dengan Metode Johansen Cointegrating Test.

3) Mengestimasi model ARDL, termasuk seleksi model dan melakukan uji diagniosa untuk menguji ada tidaknya pelanggaran asumsi-asumsi dasar ekonometri, sebelum melanjutkan ke prosedur berikutnya

4) Mengestimasi ECM berdasarkan model ARDL terpilin.

5) Menganalisis hasil output dari estimasi ECM untuk mengetahui dinamika jangka pendek.

6) Mengestimasi koefisien hubungan jangka panjang dari Model ARDL.

\section{Hasil dan Pembahasan}

\section{a. Uji Unit Akar}

Untuk mengetahui apakah data yang digunakan stasioner atau tidak, kita perlu melakukan uji unit akar (Unit root test). Uji yang biasa digunakan adalah uji 
Fadhilah, et al/Jurnal Ekonomi Syariah Teori dan Terapan Vol. 4 No. 10 Oktober 2017: 833-846; PENGARUH SERTIFIKAT BANK INDONESIA SYARIAH (SBIS), JAKARTA ISLAMIC INDEX (JII), TINGKAT INFLASI, DAN INDEX HARGA SAHAM GABUNGAN (IHSG) TERHADAP NILAI TUKAR : PENDEKATAN AUTOREGRESSIVE DISTRIBUTED LAG (ARDL)

Augmented Dickey-Fuller (ADF). Uji lain yang serupa yaitu Uji Phillips-Perron. Keduanya mengindikasikan keberadaan akar unit sebagai hipotesis null. Sekumpulan data dinyatakan stasioner jika nilai rata-rata dan varian dari data time series tersebut tidak mengalami perubahan secara sistematik sepanjang waktu, atau sebagian ahli menyatakan rata-rata dan

variannya konstan (Nachrowi dan Haridus usman, 2006)

Apabila suatu data runtun waktu (time series) tidak stasioner atau memilki akar unit, ada acara yang dapat dilakukan untuk menstasionerkan data tersebut. Salah satu caranya adalah dengan proses difference stokastik, yaitu dengan mengurangkan set data runtun waktu dengan akar unitnya. Misalkan suatu data runtun waktu memiliki persamaan akar unit:

$$
y_{t}=y_{t-1}+\mu_{t}
$$

Maka proses difference stokastiknya adalah,

$$
\Delta y_{t}=y_{t}-y_{t-1}=\mu_{t}
$$

Data runtun waktu yang tidak didifference-kan sering juga disebut sebagai data level dan memiliki lambang difference $1(0)$. Sedangkan untuk data yang telah di-difference-kan pada orde ke-n memiliki lambang difference I(n). Proses difference stokastik akan mengubah data runtun waktu yang tadinya tidak stasioner menjadi data runtun waktu yang stasioner dan memiliki rata-rata serta varians yang konstan antar periodenya. Penelitian ini menggunakan metode ADF untuk menlihat stasioneritas data. Hasil pengujian Unit Root dengan menggunakan Eviews 9 ditunjukkan pada tabel 4.1.

Berdasarkan tabel tersebut, dapat kita lihat bahwa semua variabel tidak ada yang stasioner pada tingkat Level. Hal ini ditunjukkan dari nilai probabiltas series lebih besar dari $5 \%(0,05)$. Selanjutnya, variabel diuji pada tingkat first difference. Hasilnya menunjukkan bahwa semua variabel yang diamati stasioner pada tingkat first difference.

Tabel 4.1

\begin{tabular}{|c|c|c|c|c|c|}
\hline \multicolumn{6}{|c|}{ Uji Unit Akar Pada Tingkat Level } \\
\hline Method & Statistic & Prob & Lag & $\begin{array}{l}\text { Max } \\
\text { Lag }\end{array}$ & Obs \\
\hline $\mathrm{ADF}$ - Fisher Chi-square & 13.4000 & 0.2022 & & & \\
\hline $\mathrm{ADF}$ - Choi Z-stat & -1.19952 & 0.1152 & & & \\
\hline \multicolumn{6}{|l|}{ Series } \\
\hline KURS & & 0.1176 & 0 & 9 & 41 \\
\hline JII & & 0.4736 & 0 & 9 & 41 \\
\hline INFLASI & & 0.3335 & 1 & 9 & 40 \\
\hline IHSG & & 0.5824 & 0 & 9 & 41 \\
\hline SBIS & & 0.1138 & 0 & 9 & 41 \\
\hline \multicolumn{6}{|c|}{ Uji Unit Akar Pada Tingkat First Difference } \\
\hline Method & Statistic & Prob & Lag & $\begin{array}{l}\text { Max } \\
\text { Lag }\end{array}$ & Obs \\
\hline $\mathrm{ADF}$ - Fisher Chi-square & 114.723 & 0.0000 & & & \\
\hline ADF - Choi Z-stat & -9.40317 & 0.0000 & & & \\
\hline \multicolumn{6}{|l|}{ Series } \\
\hline KURS & & 0.0000 & 0 & 9 & 40 \\
\hline JII & & 0.0000 & 0 & 9 & 40 \\
\hline INFLASI & & 0.0003 & 0 & 9 & 40 \\
\hline IHSG & & 0.0000 & 0 & 9 & 40 \\
\hline SBIS & & 0.0004 & 0 & 9 & 40 \\
\hline
\end{tabular}

Hasil Uji Unit Akar

Sumber: Data diolah

\section{b. Penentuan Panjang Lag}

Dalam melakukan regresi ARDL, kita akan dihadapkan pada pemilihan jumlah Lag yang digunakan untuk mengolah data tersebut, lag optimum merupakan cara untuk memilih seberapa besar jumlah lag yang kita gunakan dalam penelitian tersebut. sehingga pemilihan jumlah lag 
Fadhilah, et al/Jurnal Ekonomi Syariah Teori dan Terapan Vol. 4 No. 10 Oktober 2017: 833-846; PENGARUH SERTIFIKAT BANK INDONESIA SYARIAH (SBIS), JAKARTA ISLAMIC INDEX (JII), TINGKAT INFLASI, DAN INDEX HARGA SAHAM GABUNGAN (IHSG) TERHADAP NILAI TUKAR : PENDEKATAN AUTOREGRESSIVE DISTRIBUTED LAG (ARDL)

optimum sangat diperlukan agar kita memeproleh hasil yang lebih baik. Penelitian ini akan melihat jumlah Lag optimum berdasarkan hasil lag length criteria VAR. Hasil lag paling optimum ditunjukkan dari jumlah bintang terbanyak. Adapun hasil lag length criteria Pada tabel berikut menunjukkan bahwa lag optimum yang digunakan adalah Lag 6

Tabel 4.3 Lag Length Criteria

\begin{tabular}{ccccccc} 
Lag & LogL & LR & FPE & AIC & SC & HQ \\
\hline \hline 0 & -745.9061 & NA & $9.02 \mathrm{e}+11$ & 41.71700 & 41.93694 & 41.79377 \\
1 & -591.1541 & 257.9199 & $6.78 \mathrm{e}+08$ & 34.50856 & 35.82816 & 34.96914 \\
2 & -572.1809 & 26.35169 & $1.03 \mathrm{e}+09$ & 34.84338 & 37.26265 & 35.68777 \\
3 & -535.5449 & 40.70669 & $6.82 \mathrm{e}+08$ & 34.19694 & 37.71587 & 35.42514 \\
4 & -505.6852 & 24.88306 & $8.66 \mathrm{e}+08$ & 33.92696 & 38.54555 & 35.53897 \\
5 & -447.7296 & 32.19753 & $4.00 \mathrm{e}+08$ & 32.09609 & 37.81435 & 34.09192 \\
6 & -271.6671 & $48.90626^{*}$ & $1066087 .^{*}$ & $23.70373^{*}$ & $30.52166^{\star}$ & $26.08337^{\star}$
\end{tabular}

Sumber: Data Diolah

\section{c. Uji Diagnosis Model ARDL}

Sebelum melakukan analisis ARDL lebih lanjut, kita perlu melakukan uji diagnosis dari model ARDL untuk mengetahui lebih jelas apakah model ARDL yang dihasilkan adalah model yang cocok dan sempurna. Untuk melakukan uji diagnosis, pertama kita perlu memeriksa hasil Bounds Test. Uji Bounds test digunakan untuk melihat seberapa besar presentase signifikansi yang bisa kita gunakan terhadap variable yang kita teliti. Hasil uji Bounds test pada tabel 4.4 menunjukkan nilai $F$ statistik yang nilainya cukup besar, yaitu 254.4014. Nilai ini jauh lebih besar dari batas bawah nilai pada 10 dan 11. Hal ini menunjukkan bahwa hasil estimasi model ARDL bisa kita gunakan hingga signifikansi $a=1 \%$, serta hasil ini juga menunjukkan bahwa antar variable memiliki hubungan kointegrasi jangka panjang.

Tabel 4.4

ARDL Bounds Test

\begin{tabular}{|lcc|}
\hline \multicolumn{3}{l}{} \\
\hline Test Statistic & Value & $\mathrm{k}$ \\
\hline \hline F-statistic & 254.4014 & 4 \\
\hline \hline \multicolumn{3}{|c}{} \\
Critical Value Bounds & \\
\hline \hline Significance & 10 Bound & 11 Bound \\
\hline \hline $10 \%$ & 2.2 & 3.09 \\
$5 \%$ & 2.56 & 3.49 \\
$2.5 \%$ & 2.88 & 3.87 \\
$1 \%$ & 3.29 & 4.37 \\
\hline \hline
\end{tabular}

Sumber: Data diolah

Selain ARDL Bounds Test, hasil lain yang perlu kita periksa selanjutnya adalah nilai error-correction coefficient (CointEq(1)) pada model jangka pendek ECM. Nilai ini akan menunjukkan berapa besar error yang akan dikoreksi di setiap periode waktu. Agar memenuhi persyaratan, nilai ini harus negatif dan signifikan. Tabel 4.5 menunjukkan bahwa nilai CointEq(-1) pada model ini adalah -1.154943 dengan probabilitas 0.0067 , nilainya negatif dan signifikan seperti yang diharapkan. Hal ini menunjukkan bahwa $115 \%$ error pada data akan dikoreksi pada setiap periode waktu.

Tabel 4.5

\begin{tabular}{|l|l|l|l|l|}
\hline Variable & Coefficient & Std.Error & t-Statistic & Prob \\
\hline $\begin{array}{l}\text { CointEq(- } \\
1)\end{array}$ & -1.154943 & 0.012068 & - & 0.0067 \\
& & & 95.699786 & \\
\hline
\end{tabular}

Error-Correction Coefficient 
Fadhilah, et al/Jurnal Ekonomi Syariah Teori dan Terapan Vol. 4 No. 10 Oktober 2017: 833-846; PENGARUH SERTIFIKAT BANK INDONESIA SYARIAH (SBIS), JAKARTA ISLAMIC INDEX (JII), TINGKAT INFLASI, DAN INDEX HARGA SAHAM GABUNGAN (IHSG) TERHADAP NILAI TUKAR : PENDEKATAN AUTOREGRESSIVE DISTRIBUTED LAG (ARDL)

\section{d. Analisi Jangka Pendek ECM}

Hasil jangka pendek model ARDL dapat dilihat dari model ECM nya. Model ECM ini diperoleh dengan menggunakan metode general to specific yang diawali dari lag maksimum lalu dengan prosedur tes standar mengeliminasi variablevariabel ARDL yang secara spesifik tidak signifikan, hingga diperoleh hasil paling sederhana (parsimonius regression). Langkah ini tidak dilakukan penulis secara manual, karena Eviews 9 yang digunakan sudah memiliki opsi $A R D L$, sehingga hasil yang diinginkan ini sudah otomatis didapatkan. Hasil ECM ini memiliki beberapa lag yang signifikan, namun penulis hanya akan mengambil salah satu contoh variable sebagai gambaran umum estimasi jangka pendek. Tabel 4.6 berikut menunjukkan sampel hasil estimasi jangka pendek ECM. Adapun hasil lebih lengkapnya termuat dalam lampiran.

Tabel 4.6

Model Jangka Pendek ECM

\begin{tabular}{|l|l|l|l|l|}
\hline Variable & Coefficient & Std.Error & t-Statistic & Prob \\
\hline DLOG(JII) & -0.642055 & 0.019971 & -32.14973 & 0.0198 \\
\hline DLOG(INFLAS & 0.003972 & 0.000856 & 4.637113 & 0.1352 \\
\hline DLOG(IHSG) & -0.452033 & 0.025029 & 18.060580 & 0.0352 \\
\hline DLOG(SBIS) & -0.136380 & 0.011290 & 12.080022 & 0.0526 \\
\hline Cointeq(-1) & -1.154943 & 0.012068 & -95.69978 & 0.0067 \\
\hline
\end{tabular}

Sumber: Data diolah

Estimasi ECM dari tabel diatas menunjukkan bahwa variabel Jakarta Islamic Index (JII), Index Harga Saham Gabungan (IHSG), dan Sertifikat Bank Indonesia Syariah (SBIS) memiliki hasil signifikan dan positif terhadap Kurs IDR/USD, sedangkan variabel inflasi memiliki nilai yang positif dan tidak signifikan. Adapun persamaan yang terbentuk dari tabel tersebut adalah sebagai berikut:

DLOG(KURS) $=-0.642055(\mathrm{DLOG}(\mathrm{JII}))+$ 0.003972* (DLOG(INFLASI)) -

0.452033 (DLOG(IHSG)) -

0.136380 (DLOG(SBIS)) - 1.154943

*Tidak signifikan

Variabel harga saham JII dan IHSG sama-sama memiliki nilai yang negatif., yang berarti jumlah Rupiah yang digunakan untuk membeli Dollar berkurang sehingga Rupiah terapresiasi. Hal ini sesuai dengan penelitian yang dilakukan oleh Benjamin M. Tabak (2006), dimana harga saham secara linier mempengaruhi nilai tukar dengan nilai negatif. Naiknya index saham menandakan perusahan-perusahaan yang termasuk dalam index mengalami peningkatan. Hal ini menyebabkan investor akan tertarik untuk menanamkan modalnya di Indonesia karena dianggap akan memberikan return yang tinggi. Masuknya investor ke Indonesia akan meningkatkan jumlah permintaan Rupiah meningkat, sehingga Rupiah akan terapresiasi terhadap Dollar Amerika.

Hasil ini juga mendukung studi yang dilakukan oleh Richard \& John (2009) dimana harga saham signifikan secara negative mempengaruhi nilai tukar. Studi ini juga menyatakan bahwa harga saham 
Fadhilah, et al/Jurnal Ekonomi Syariah Teori dan Terapan Vol. 4 No. 10 Oktober 2017: 833-846; PENGARUH SERTIFIKAT BANK INDONESIA SYARIAH (SBIS), JAKARTA ISLAMIC INDEX (JII), TINGKAT INFLASI, DAN INDEX HARGA SAHAM GABUNGAN (IHSG) TERHADAP NILAI TUKAR : PENDEKATAN AUTOREGRESSIVE DISTRIBUTED LAG (ARDL)

merupakan salah satu faktor paling dominan yang mempengaruhi nilai tukar di Australia. Namun hasil ini bertentangan dengan beberapa sampel penelitian yang dilakukan oleh Mohsen (2015), dimana salah satu sampel dari Negara yang diteliti menyatakan bahwa saham dan nilai tukar berhubungan positif.

Variabel SBIS juga menunjukkan nilai signifikan negatif, dimana nilainya 0.136380 dengan probabilitas 0.0526 . Hasil ini mendukung penelitian yang dilakukan oleh Prof. Pareshkumar (2014) dan Katarzyna (2014) yang menyatakan suku bunga (dalam hal ini bagi hasil) berpengaruh signifikan negatif terhadap nilai tukar. Meningkatnya nilai SBIS akan mendorong kenaikan selisih antara bagi hasil di Indonesia dengan bagi hasil atau suku bunga luar negeri. Dengan melebarnya selisih suku bunga tersebut mendorong investor asing untuk menanamkan modal ke dalam instrument-instrumen keuangan di Indonesia seperti SBIS karena mereka akan mendapatkan tingkat pengembalian yang lebih tinggi. Aliran modal masuk asing akan mendorong apresiasi nilai tukar Rupiah. Hasil ini berbeda dengan penelitian yang dilakukan Ravinran dan Soroush (2015) di Malaysia yang menyatakan bahwa suku bunga mempengaruhi nilai tukar secara positif.

Variabel inflasi menunjukkan nilai positif 0.003972 dan nilai probabilitas
0.1352 yang berarti lebih besar dari $a$, sehingga tidak signifikan. Hasil ini sesuai dengan penelitian yang dilakukan oleh Ebiringa dkk (2014) dimana Variabel inflasi memiliki nilai positif yang berarti kenaikan tingkat inflasi akan mengakibatkan Rupiah depresiasi, namun tidak berpengaruh signifikan. Pada umumnya, kenaikan tingkat inflasi akan membuat harga barang domestik terlihat lebih mahal dibanding harga barang internasional. Hal ini menyebabkan orang asing enggan untuk membeli produk domestik sehingga nilai tukar Rupiah akan mengalami depresiasi. Namun sepanjang tahun 2016 , inflasi di Indonesia berada pada tingkat yang relatif aman, yaitu dibawah $4 \%$. Oleh karena itu, faktor ini lah yang kemungkinan besar menyebabkan tingkat inflasi tidak berpengaruh signifikan terhadap Kurs.

\section{e. Analisis Jangka Panjang ARDL}

$$
\text { Estimasi jangka panjang }
$$
merupakan hal yang diunggulan dalam penggunaan model ARDL. Dengan menggunakan model ini, kita bisa menganalisis hubungan jangka panjang ketika variabel variabel penjelasnya campuran antara yang bersifat I(1) dan I(0). Estimator ARDL akan meghasilkan koefisien jangka panjang yang konsisten diaman estimasi yang dihasilkan konsisten dengan koefisien jangka panjang yang bagus tanpa peduli apakah variabelvariabel penjelasnya atau regresornya I(0) ataupun I(1). Tabel 4.6 berikut 
Fadhilah, et al/Jurnal Ekonomi Syariah Teori dan Terapan Vol. 4 No. 10 Oktober 2017: 833-846; PENGARUH SERTIFIKAT BANK INDONESIA SYARIAH (SBIS), JAKARTA ISLAMIC INDEX (JII), TINGKAT INFLASI, DAN INDEX HARGA SAHAM GABUNGAN (IHSG) TERHADAP NILAI TUKAR : PENDEKATAN AUTOREGRESSIVE DISTRIBUTED LAG (ARDL)

menunjukkan hasil estimasi jangka panjang ARDL.

Tabel 4.7

Estimasi Jangka Panjang ARDL

\begin{tabular}{|l|l|l|l|l|}
\hline Variable & Coefficient & Std.Error & t-Statistic & Prob \\
\hline LOG(JII) & -4.135491 & 0.167601 & -24.674601 & 0.0268 \\
\hline LOG(INFLASI) & -0.014160 & 0.006860 & -2.064168 & 0.2872 \\
\hline LOG(IHSG) & 4.031438 & 0.154626 & 26.072171 & 0.0244 \\
\hline LOG(SBIS) & -1.935375 & 0.107889 & -17.938609 & 0.0355 \\
\hline C & 5.803606 & 0.283619 & 20.462674 & 0.0311 \\
\hline
\end{tabular}

Sumber: Data diolah

Estimasi jangka panjang ARDL dari tabel diatas menunjukkan bahwa variabel Jakarta Islamic Index (JII), dan Sertifikat Bank Indonesia Syariah (SBIS) memiliki hasil signifikan dan positif terhadap Kurs IDR/USD, sedangkan variabel inflasi memiliki nilai yang negatif namun tidak signifikan, serta variabel Index Harga Saham Gabungan (IHSG) memiliki nilai positif dan signifikan. Adapun persamaan yang terbentuk dari tabel tersebut adalah sebagai berikut:

LOG $($ KURS $)=5.803606-4.135491($ LOG $(\mathrm{JII}))$

- 0.014160* (LOG(INFLASI)) + 4.031438

(LOG(IHSG)) - 1.935375 (LOG(SBIS)) ...(4.4)

*Tidak signifikan

Sama seperti pada jangka pendek, variable Jakarta Islamic Index (JII) pada jangka panjang memiliki nilai signifikan negatif dimana nilai koefisiennya -4.135491 dan probabilitas 0.0268. Ini berarti seiring dengan meningkatnya JII, investor akan tertarik untuk menanamkan modalnya di
Indonesia karena dianggap akan memberikan return yang tinggi. Masuknya investor ke Indonesia akan meningkatkan jumlah permintaan Rupiah meningkat, sehingga Rupiah akan terapresiasi terhadap Dollar Amerika. Hasil ini mendukung penelitian yang dilakukan oleh Benjamin M. Tabak (2006) dan Richard (2009), dimana harga saham secara linier mempengaruhi nilai tukar secara negatif.

Berbeda dengan hasil pada jangka pendek, variable IHSG memiliki nilai positif signifikan terhadap nilai tukar Rupiah dimana dinali koefisiennya 4.031438 dengan probabilitas 0.0244 . Hal ini berarti meningkatnya IHSG justru akan menyebabkan nilai tukar Rupiah terhadap Dollar terdepresiasi. Hasil ini mendukung penelitian yang dilakukan oleh Richard \& John (2009), yang menyatakan bahwa pengaruh variable harga saham terhadap nilai tukar memang berbeda beda tergantung negara dan jangka waktunya. Hal ini disebabkan karena variable harga saham juga dipengaruhi oleh spekulasi dari Investor sendiri, sehingga hasil yang diberikan bisa berbeda beda. Faktor lain yang mungkin menjadi penyebabnya adalah, seperti yang kita ketahui bahwa variable IHSG juga menunjukkan pertumbuhan perekonomian Indonesia. Apabila IHSG meningkat, maka perekonomian Indonesia sedang baik, dan apabila IHSG turun, maka perekonomian sedang terganggu. Pada tahun 2016, tren IHSG cenderung 
Fadhilah, et al/Jurnal Ekonomi Syariah Teori dan Terapan Vol. 4 No. 10 Oktober 2017: 833-846; PENGARUH SERTIFIKAT BANK INDONESIA SYARIAH (SBIS), JAKARTA ISLAMIC INDEX (JII), TINGKAT INFLASI, DAN INDEX HARGA SAHAM GABUNGAN (IHSG) TERHADAP NILAI TUKAR : PENDEKATAN AUTOREGRESSIVE DISTRIBUTED LAG (ARDL)

menigkat, dan hal ini juga diikuti oleh pertumbuhan perekonomian yang bagus. Pertumbuhan ekonomi yang meningkat menyebabkan banyak pihak-pihak yang justru meningkatkan Import dan membayar hutang. Meningkatnya jumlah import dan pembayaran hutang luar negeri ini diperkirakan menjadi faktor yang menyebabkan nilai IHSG positif terhadap nilai tukar Rupiah.

Selanjutnya variable SBIS dalam jangka panjang memiliki nilai negatif dan signifikan yang sama dengan jangka pendek dimana nilai koefisiennya 1.935375 dan nilai probabilitas 0.0355 . Hasil ini juga berarti mendukung penelitian yang dilakukan oleh Prof. Pareshkumar (2014) dan Katarzyna (2014) yang menyatakan suku bunga (dalam hal ini bagi hasil) berpengaruh signifikan negatif terhadap nilai tukar. Meningkatnya nilai SBIS akan mendorong kenaikan selisih antara bagi hasil di Indonesia dengan bagi hasil atau suku bunga luar negeri. Dengan melebarnya selisih suku bunga tersebut mendorong investor asing untuk menanamkan modal ke dalam instrument-instrumen keuangan di Indonesia seperti SBIS karena mereka akan mendapatkan tingkat pengembalian yang lebih tinggi. Aliran modal masuk asing akan mendorong apresiasi nilai tukar Rupiah.

Variabel tingkat inflasi dalam jangka panjang juga tidak berpengaruh signifikan seperti jangka pendek. Namun nilai yang dihasilkan justru negatif, yang berarti berbeda pada teori umum kebanyakan. Nilai koefisien inflasi yang dihasilkan adalah -0.014160 dan nilai probabilitas 0.2872 yang berarti lebih besar dari a.. Hasil ini mendukung penelitian yang dilakukan oleh Ravindran dan Soroush (2015), dimana pengaruh variabel Inflasi terhadap nilai tukar berbeda dari teori secara umum. Nilai negatif menunjukkan bahwa apabila inflasi meningkat justru akan menyebabkan rupiah mengalami apresiasi. Salah satu faktor yang mungkin mendasari hasil ini adalah, karena trend inflasi di Indonesia cenderung stabil, dimana pada tahun 2016, nilainya berada dalam batas aman yaitu di bawah $4 \%$. Selama masih dalam batas aman, Inflasi justru bisa meningatkan perekonomian. Dalam hal ini, Inflasi akan mengakibatkan masyarakat lebih konsumtif karena khawatif harga barang di masa depan menjadi lebih mahal. Hal ini menyebabkan perputaran uang dan pertumbuhan ekonomi meningkat.

\section{f. Perbedaan Instrument Ekonomi Moneter} Islam Dan Konvensional Dalam Mempengaruhi Nilai Tukar Rupiah

Penelitian ini menyertakan dua instrument ekonomi moneter yang berbeda, yaitu ekonomi moneter konvensional yang diwakili Index Harga Saham Gabungan dan ekonomi moneter islam yang diwakili oleh Sertifikat Bank Indonesia Syariah (SBIS). Adapun yang akan peneliti bahas lebih lanjut adalah perbedaan Jakarta Islamic Index dan 
Fadhilah, et al/Jurnal Ekonomi Syariah Teori dan Terapan Vol. 4 No. 10 Oktober 2017: 833-846; PENGARUH SERTIFIKAT BANK INDONESIA SYARIAH (SBIS), JAKARTA ISLAMIC INDEX (JII), TINGKAT INFLASI, DAN INDEX HARGA SAHAM GABUNGAN (IHSG) TERHADAP NILAI TUKAR : PENDEKATAN AUTOREGRESSIVE DISTRIBUTED LAG (ARDL)

Index Harga Saham Gabungan dalam mempengaruhi Nilai Tukar Rupiah karena keduanya merupaan variable yang sama, yaitu saham.

Berdasarkan hasil yang ditunjukkan dengan menggunakan metode ARDL, dapat kita lihat bahwa hasil yang diperoleh Jakarta Islamic Index adalah sama baik dalam jangka panjang maupun jangka pendek, yaitu signifikan negatif. Sementara hasil yang diperoleh oleh Index Harga Saham Gabungan adalah signifikan negatif di jangka pendek dan signifikan positif di jangka panjang. Hal ini menunjukkan ada perbedaan yang cukup besar antara IHSG dan JII, dimana hasil dari JII lebih stabil dan konstan sementara hasil dari IHSG berflukuatif. Perbedaan yang lebih jelas ditunjukkan dalam grafik 4.1 berikut.

Grafik 4.1

Grafik JII dan IHSG

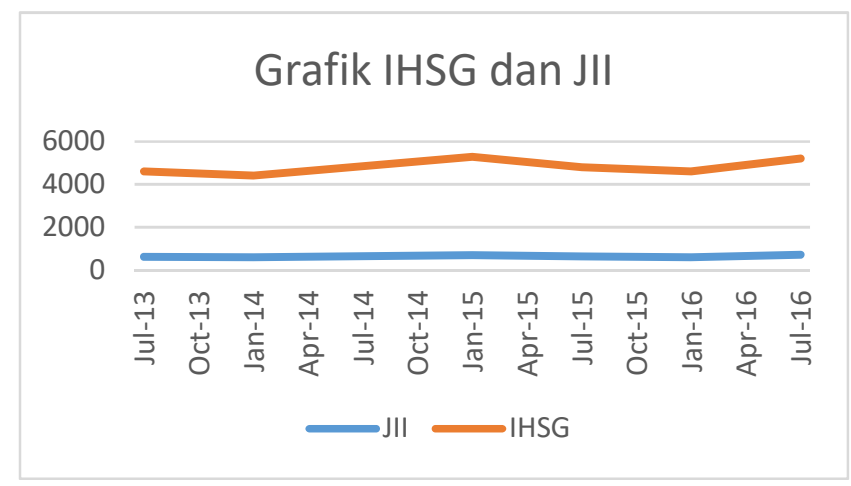

Sumber: Data Diolah

Berdasarkan grafik 4.1 diatas, dapat kita lihat perbedaan pergerakan Jakarta Islamic Index dan Index Harga Saham Gabungan. IHSG cenderung berfluktuatif dari tahun ke tahun, sementara JII cenderung stabil dari tahun ke tahun. Hal ini mendukung teori ekonomi islam yang salah satunya diungkapkan oleh Syafi'i Antonio dalam Republika (15/10/2016) yang menyatakan bahwa instrument ekonomi islam cenderung mempunyai hasil yang stabil dan tidak terpengaruh oleh gejolak perekonomian, termasuk dalam pasar modal syariah. Hal ini karena sistem ekonomi syariah mendorong keseimbangan pengembangan sektor riil dan non riil yang ditunjukan dengan keharusan adanya underlying asset dalam menyalurkan pembiayaan. Jika melihat grafik ini, kita bisa berkesimpulan bahwa apabila kita menginvestasikan dana kita pada instrument keuangan konvensional, maka akan ada kemungkinan dimana kita bisa untung besar dan rugi besar, sehingga hasil yang diberikan tidak pasti. Berbeda dengan apa bila kita menyalurkan dana pada investasi syariah JII, maka hasil yang diberikan akan lebih stabil dan cenderung tidak terpengaruh oleh gejolak perekonomian baik dalam negeri maupun luar negeri.

\section{Kesimpulan.}

Kestabilan nilai tukar rupiah merupakan salah satu faktor penting untuk menjaga stabilitas perekonomian. Oleh karena itu, pemerintah melalui berbagai lembaga seperti Bank Indonesia dan Otoritas Jasa Keuangan senantiasa berusaha menjaga kestabilan nilai tukar rupiah. Nllai tukar rupiah dipengaruhi oleh berbagai faktor, seperti diantaranya yang dibahas dalam penelitian ini adalah 
Fadhilah, et al/Jurnal Ekonomi Syariah Teori dan Terapan Vol. 4 No. 10 Oktober 2017: 833-846; PENGARUH SERTIFIKAT BANK INDONESIA SYARIAH (SBIS), JAKARTA ISLAMIC INDEX (JII), TINGKAT INFLASI, DAN INDEX HARGA SAHAM GABUNGAN (IHSG) TERHADAP NILAI TUKAR : PENDEKATAN AUTOREGRESSIVE DISTRIBUTED LAG (ARDL)

Sertifikat Bank Indonesia Syariah, Jakarta islamic Index, Index Harga Saham Gabungan, dan juga inflasi. Penelitian ini menggunakan metode Autoregressive Distributed Lag (ARDL), dimana salah satu keunggulannya adalah analisis varibael dalam jangka panjang.

Hasil ARDL menunjukkan bahwa semua variable memiliki pengaruh yang signifikan baik pada jangka panjang maupun jangka pendek, kecuali variable Inflasi yang hanya signifikan di jangka pendek pada lag tertentu. Dalam jangka pendek, variable JII, IHSG, dan SBIS berpengaruh signifikan negatif yang berarti meningkatnya variable tersebut akan menyebabkan Rupiah terapresiasi terhadap Dollar Amerika. Dalam jangka panjang variable JII dan SBIS juga bernilai negatif dan signifikan, sedangkan variable IHSG bernilai positif dan variable Inflasi bernilai negatif tidak signifikan

\section{Daftar Pustaka}

Al-Qur'an. 2014. Al-Qur'an dan Terjemahnya. Kementrian Arab Saudi. Madinah: Kompleks Percetakan AlQur'an Raja Fahd.

Arifin, Zainul. 2005. Dasar-dasar Manajemen Bank Syariah. Jakarta: Pustaka Alvabet.

Ascarya. 2012. Alur Transmisi dan Efektifitas Kebijakan Moneter Ganda di Indonesia. Buletin Ekonomi Moneter dan Perbankan. Bi.go.id

2010. Peran Perbankan Syariah dalam Transmisi Kebijakan Moneter Ganda di Indonesia. Iqtisodia, Republika, August 26.

Ardrabiz. 2011. Pengaruh Tingkat Inflasi Terhadap Kurs Valuta Asing. (diakses pada 3 Desember 2016 di https://ardra.biz/ekonomi/analisisfundamental-ekonomi/pengaruh-inflasiterhadap-kurs/).

Aloi, Riadh dan Mohamed Safouane. 2016. rRelationship Between Oil Price, Stock Price, and Exchange Rate: a Vine Copula Based GARCH Method. Elsevier

Bank Indonesia. Peraturan Bank Indonesia (PBI) Nomor 10/1 1/PBI/2008 tentang SBIS

(PBI) Nomor 2/9/PBI/2004 tentang pencabutan SWBI (Sertifikat Wadiah Bank Indonesia)

(PBI) Nomor pencabutan SWBI (Sertifikat Wadiah Bank Indonesia)

tanggal 14 Oktober 2016 di http://www.bi.go.id/id/moneter/birate/data/Default.aspx).

$\begin{array}{ccc} & \text { Siaran Pers BI Rate. } \\ \text { tanggal } & 14 & \text { oktober diakses }\end{array}$ http://www.bi.go.id/id/ruangmedia/siaranpers/Pages/sp_189616.aspx)

Bursa Efek Indonesia. 2014. Mengenal Pasar Modal Indonesia. (diakses tanggal 3 Desember 2016 di http://www.idx.co.id/id-

id/beranda/informasi/bagiinvestor/pen gantarpasarmodal.aspx)

Badan Pusat Statistik. 2016. Statistik Pertumbuhan Perekonomian Indonesia. (diakses tanggal 5 Desember di https://www.bps.go.id/)

Chapra, M. Umer. 1985. Towards a Just Monetary System. Leicester, UK: The Islamic Foundation

Dewan Syariah Nasional. 2007. fatwa DSNMUI No. 64/DSN-MUI/XII/2007 tentang Sertifikat Bank Indonesia Syariah Ju'alah

Ebiringa, dkk. 2014. Exchange Rate, Inflation, and Interest Rates Relationships : AnAutoregressive Distributed Lag Analysis. America: Research Institute for Policy Development. 
Fadhilah, et al/Jurnal Ekonomi Syariah Teori dan Terapan Vol. 4 No. 10 Oktober 2017: 833-846; PENGARUH SERTIFIKAT BANK INDONESIA SYARIAH (SBIS), JAKARTA ISLAMIC INDEX (JII), TINGKAT INFLASI, DAN INDEX HARGA SAHAM GABUNGAN (IHSG) TERHADAP NILAI TUKAR : PENDEKATAN AUTOREGRESSIVE DISTRIBUTED LAG (ARDL)

Eric, Yuliana. 2000. Sistem Nilai Tukar dan Solusinya. Jakarta: PT Gramedia Pustaka Utama

EViews 9. 2016. User's guide. (diakses tanggal 5 Oktober 2016 di http://www.eviews.com/help/helpintro. html\#page/content\%2Fpreface.html\%2 3)

Falianty, Telisa. A. 2003. Exchange Rate Overshooting : Sebuah Studi Empiris di Indonesia dalam Sistem Nilai Tukar Mengambang. Tesis Pada Program Pascasarjana Ilmu Ekonomi, Fakultas Ekonomi Universitas Indonesia (tidak diterbitkan).

Gujarati, Damodar. 2003. Basic Econometrics. New York: Mc Graw-Hill.

Ghozali, Imam. 2011. Aplikasi Analisis Multivariate Dengan Prograam IBM.

Semarang: Universitas Diponogoro

Giles, Dave Professor. 2015. ARDL Modeling in Eviews. (diakses pada 27 November 2016

di: http://davegiles.blogspot.co.id/2015/01 /ardl-modelling-in-eviews-9.html)

Hanafi.M 2003. Manajemen keuangan Internasional. Yogyakarta: BPFE

Halwani, Hendra. 2005. Ekonomi Internasional dan Globalisasi Ekonomi. Bogor: Ghalia Indonesia

Hakim, Arif Rahman. 2015. Pengantar Time Series: Stasioneritas, Akar unit, dan kointegrasi. Depok (Modul tidak dipublikasikan)

Huda, Nurul. 2013. Ekonomi Makro Islam Pendekatan Teoritis. Jakarta: Kencana

Indonesia Value Investor. 2015. Rupiah dan IHSG. (diakses tanggal 14 oktober 2016 http://www.teguhhidayat.com/2010/05 /rupiah-ihsg.html).

Islamiyah, Suaibatul. 2012. Penerapan Autoregressive Distributed Lag (Ardl) Dalam Memodelkan Pengaruh Harga Minyak Dunia Dan Jumlah Uang Beredar Terhadap Inflasi Di Indonesia. Jurnal Universitas Brawijaya.
Karim, Adiwarman. 2002. Ekonomi Islam: Suatu Kajian Ekonomi Makro. Jakarta: IIT Indonesia

2004. Sejarah Pemikiran Ekonomi Islam. Jakarta, Indonesia: Rajawali Pers

Kompas. 4 Oktober 2015. Saham dan Nilai Tukar Rupiah. hlm.11.

Kuncoro, Mudrajad, 2011. Metode Kuantitatif: Teori dan Aplikasi Untuk Bisnis dan Ekonomi. Yogyakarta: UPP STIM YKPN

Katadata. Maret 2015. Dua Sisi Dampak Penurunan $\mathrm{Bl}$ Rate. (Diakses tanggal 2 Desember $2016 \quad$ di http://katadata.co.id/berita/2015/03/0 4/dua-sisi-dampak-penurunan-bi-rate).

Mankiw, Gregory N. Teori Makro Ekonomi. Jakarta: Erlangga

Nasution. 2003. Metode Research. Jakarta: PT. Bumi Aksara

Otoritas Jasa Keuangan. Pasar Modal Syariah. (diakses pada 5 Desember 2016

di http://www.ojk.go.id/id/kanal/syariah/† entang-syariah/pages/pasar-modalsyariah.aspx)

Modal Syariah. Desember 2016 pada 5 http://www.ojk.go.id/id/kanal/syariah/r egulasi/peraturan-pasar-modal-syariah)

Oskoee, Mohsen Bahmani. 2015. Do Exchange Rate Have Symetric or Asymetric effect on Stock Price?. Global Finance Journal Elsevier

Fatwa DSN-MUI Terkait Lembaga Keuangan Syariah. (diakses pada 5 Desember 2016 di http://www.ojk.go.id/id/kanal/syariah/r egulasi/fatwa-dsn-mui).

Patel, Pareshkumar. 2014. Factors Affecting Currency Exchange Rate, Economimcal Formulasm and Prediction Models. International Journal of Application and Innovation in Engineering \& Management

Pesaran, M. Hashem, and Yongcheol Shin. 1998. "An Autoregressive Distributed 
Fadhilah, et al/Jurnal Ekonomi Syariah Teori dan Terapan Vol. 4 No. 10 Oktober 2017: 833-846; PENGARUH SERTIFIKAT BANK INDONESIA SYARIAH (SBIS), JAKARTA ISLAMIC INDEX (JII), TINGKAT INFLASI, DAN INDEX HARGA SAHAM GABUNGAN (IHSG) TERHADAP NILAI TUKAR : PENDEKATAN AUTOREGRESSIVE DISTRIBUTED LAG (ARDL)

Lag Modelling Approach to Cointegration Analysis". In Econometrics and Economic Theory in the 20th Century: The Ragnar Frisch Centenial Symposium, ed. Steiner Strom. Cambridge: University of Cambridge.

1995.

"An Autoregressive Distributed Lag Modelling Approach to Cointegration Analysis". DAE Working Paper no. 9514. Cambridge: University of Cambridge

Ramasamy, Ravindran dan Abar Soroush K. 2015. Influence of Macroeconomic Variables on Exchange Rates. Journal of Economic Economics, Business and Management Tun Abdul Razak University.

Richard, Noel Dilrukshan and John Simson. 2009. The Interaction Between Exchange Rates and Stock Prices: an Australian Context. Australia: International Journal of Economics an Finance CCSE

Rosyidi, Suherman. 2011. Pengantar Teori Ekonom: Pendekatan Kepata Teori Ekonomi Makro dan Mikro. Rajawali Pers

Rosadi, D. 2011, Analisis Ekonometrika \& Runtun Waktu Terapan. Yogyakarta. hal. 197-200.

Sahamok. 2016. Jakarta Islamic Index. (diakses tanggal 2 Desember 2016 di http://www.sahamok.com/bei/indeksbursa/jakarta-islamic-index-jii/) .

Sakti, Ali. 2007. Sistem Ekonomi Islam: Jawaban atas Kekacauan Ekonomi Modern. Jakarta, Indonesia: Paradigma \& Aqsa Publishing
Salomo, Ronny. 2007. Peranan Perdagangan Internasional Sebagai Salah Satu Sumber Pertumbuhan Ekonomi Indonesia. Departemen Perdagangan R.I Program Pascasarjana IImu Ekonomi.

Sekuritas. Mengenal Apa Itu IHSG. (diakses tanggal 3 Desember 2016 di http://sekuritas.co.id/mengenal-apaitu-ihsg/)

Syafi'i, Muhammad Anthonio. 2010. Bank Syariah dari Teori ke Praktik. Jakarta: Gema Insani

Tarmizi, Erwandi. 2013. Harta Haram Muamalat Kontemporer. Bogor: BMI Publishing

Triyono, Teguh. 2005. Ekonomi Internasional. Jakarta: Erlangga

Twarowska, Katarzyna. 2014. Analysis of Factors Affecting Fluctuation in the Exchange Rate of Polish Zloty Against Euro. Slovenia International Conference

Universitas Airlangga. 2009. Pedoman Penulisan Pembimbingan Dan Ujian Skripsi Fakultas Ekonomi dan Bisnis. Surabaya.

Wilson, Lungu and Sheefeni Johannes. 2014. The Relationship Between Interest Rate and Exchange Rate in Namibia. International Monthly Journal of Emerging Issue in Economics, Finance, and Banking.

Wirdianingsih, dkk. 2005. Bank Dan Asuransi Islam Di Indonesia. Jakarta: kencana

Wong, Hock Tsen. 2013. Real Exchange Rate Misalignmennt And Economic Growth in Malaysia. Malaysia: Emerald Group Publishing. 